\title{
Die Ou Testament oor demone en die Satan 1
}

\author{
W. Vosloo \\ Sentrum vir Voortgesette Teologiese Opleiding \\ Universiteit van Pretoria \\ PRETORIA
}

In die lig van die Bybel glo ek nie in die Satan nie. 'n Christen glo net in God, en kan dus nie ook in die Satan glo nie, want dit sou vertroue en 'n persoonlike verhouding impliseer. Miskien moet ek eerder saam met Otto Weber sê: "Ons glo teen die duiwel"! Hierdie onderskeid is nodig omdat te veel Christene soveel statuur aan die Satan gee dat dit God verdwerg. In sy Screwtape Letters skryf die gevierde C.S. Lewis:

There are two equal and opposite errors into which our race can fall about devils. One is to disbelicve in their existence. The other is to believe, and to feel an excessive and unhealihy interest in them.

Daarmee het Lewis die tweekantige, kontrasterende gevaar oor die Bose verwoord: enersyds die ontkenning van sy bestaan en andersyds die aanvaarding daarvan op so 'n wyse dat dit neerkom op verering van die Satan. Die laaste gevaar is vandag wesenlik, veral onder ons jeug, sodat met erns gevra kan word: Hoe kan ons verhoed dat die Bose tot die held verhef word. Om dié vraag te beantwoord, moet ons allereers vasstel wat die Bybel oor die saak te sê het.

Die Ou Testament is by uitstek die boek oor God; daarom word daar maar min na demone, die Satan of die bose as bomenslike wese(ns) verwys. En wanneer dit wel gedoen word, gebeur dit op 'n bepaalde wyse.

\section{DEMONE}

Opvattings oor demone is redelik algemeen onder primitiewe volke en dit het sy oorsprong in animistiese sieninge oor vreemde voorwerpe en verskynsels. So het mense destyds maklik geglo dat 'n boom of rots met 'n ongewone vorm die vergestalting van een of ander demoon of gees was.

In Israel was daar 'n besliste standpunt teen sulke opvattings. Die blote feit dat die Ou Testament Israeliete verbied om hulle met hierdie soort dinge in te laat, toon egter dat die gewone mense hulle tog hierdeur laat beinvloed het. Dis waarom Levitikus 17:7 lui: "Die Israeliete mag nooit weer diere slag vir veldgode en so aan die Here ontrou

1 'n Verwerking van 'n referaat oorspronklik aangebied tydens 'n seminaar oor Salanisme, aangebicd deur dic Sentrum vir Teologiese Opleiding aan dic Universiteit van Preloria. 
wees nie." Dat die gewone Israeliete hulle ook met die oproep van geeste en beswering besiggehou het, blyk uit Levitikus 19:31: "Moenie hulp soek by geeste en waarsêers nie" en uit die besonder streng bestraffing in Levitikus 20:27: "Enige mens wat hom ophou met die oproep van geeste of met beswering, moet doodgemaak word. Hy moet met klippe doodgegooi word. Hy verdien die dood." Met ander woorde, hoewel hierdie soort praktyke afgekeur en swaar gestraf is, het mense dit $\log$ nog beoefen.

In die Ou Testament word drie demone genoem:

\subsection{Lath}

Lîlit, wat in Jesaja 34:14 as die naggees vertaal word. Die opvatting oor so 'n demoon kom oorspronklik uit Mesopotamië. Die Sumeriërs het destyds al gepraat van 'n vroulike stormdemoon, Lilitu wat in die woestyn sou gewoon het. Die naam is van die woord $\| l l$ afgelei en is later as "nag" (Hebreeus: lajelah) verstaan, vandaar die vertaling "naggees". Na aanleiding van Jesaja 34:14 het allerlei legendes rondom hierdie figuur ontstaan en het dit ingang gevind in Joodse geskrifte (veral in die geskrifte van die mistieke Kabbala). Geleidelik word dit die benaming van 'n vroulike vampier. Mettertyd het dit ook by die Christendom ingang gevind en in Westerse literatuur soos Faust 'n rol gespeel. Vandag word die karakter in allerlei spanningsverhale teëgekom en in rillerrolprente in een of ander vorm 'n plek gegee.

\subsection{Sjâ̂}

Die demoon Sja'îr word in Jesaja 13:21; 34:14; Levitikus 17:7 en 2 Kronieke 11:15 as "veldduiwel of "veldgod" vertaal. Hierdie benaming is afgelei van 'n woord wat die harige een of die bokram beteken en wat verband hou met die sater van die Griekse mitologie wat halfmens en halfbok sou wees. Die uitdrukking satiries hou verband hiermee.

\section{Sjeed}

Die Ou Testament vermeld nog een demoon, naamlik Sjeed, of in die meervoud, Sjeedim. Dit word in Deuteronomium 32:17 en Psalm 106:37 met "veldduiwels" vertaal. Die oorsprong van die benaming is onseker, maar dis moontlik dat dit afgelei is van sjoed, die woord vir "swart" of van sjaddad (verwoes of verlate maak).

Daar is ook enkele ander moontlike verwysings na demone:

- Alhoewel Asasel van Levitikus 16:10 en 22 soms as een of ander woestyndemoon beskou word, bestaan daar genoeg rede om te aanvaar dat dit eerder "algehele vernietiging" beteken en nie na 'n wese verwys nie.

- Sommige mense beskou Leviatan (bv. Jes. 27:1) en Rahab (bv. Job 26:12) ook as verwysings na demone. In die lig van die mitologiese seemonsterfigure van Israel se bure moet dit eerder gesien word as personifikasie van die oermagte wat die 
skepping bedreig het, maar deur die Here vernietig is.

- Die verwysing in 1 Samuel 16:14 na die bose gees wat die Here oor Saul gestuur het, word somtyds ook in terme van 'n demoon uitgelê. Dit moet egter onthou word dat mense destyds enigiets wat vreemd gelyk of onverklaarbar opgetree het aan die teenwoordigheid van 'n bonatuurlike wese toegeskryf het. Soortgelyk is Saul se vreemde optredes in die volksmond toegeskryf aan die werking van 'n bose gees. Vandag word aanvaar dat hy geestelik versteurd was.

Die Ou-Testamentiese verwysings na hierdie demone is nie noodwendig 'n onderskrywing van die bestaan van sulke wesens nie. In Levitikus 17:7 en Deuteronomium 32:17 word die verering van sulke voorstellings verbied, en in 2 Kronieke 11:5 en Psalm 106:37 word die praktyke met afkeur vermeld. Jesaja (13:21 en 34:14) verwys daarna bloot in terme van die populêre opvattings van die mense van destyds en noem hulle in een asem met die wilde diere. In Deuteronomium 32:17 word dit uitdruklik gesê dat hierdie gewaande wesens "niegode" is. Hoewel die praktyke dus erken word, kan daar nie uit die vermeldings afgelei word dat die Ou Testament die werklike bestaan van hierdie wesens bevestig nie. Ou oorlewerings, heidense opvattings en gebruike, die probleem van die onbekende en die vrese van mense speel almal ' $n$ belangrike rol in die populêre geloof in die bestaan van hierdie wesens waarvan die Ou Testament praat.

\section{DIE SATAN}

Die Bybel verskaf nie genoeg inligting oor die oorsprong van die Satan nie. Hierdie gebrek aan informasie gee aanleiding tot velerlei spekulasies. Daarom is dit nodig om eers 'n aantal vermeende verwysings na die Satan te bespreek en daarna aandag te gee aan die paar plekke in die Ou Testament waar die Hebreeuse woord satan dalk wel op die Satan kan dui.

\subsection{Vermeende verwysings na die Satan}

\subsubsection{Genesis 3}

Baie mense dink dat 'n mens uit die gebeurtenisse in Genesis 3 rondom Adam en Eva en die slang antwoorde kan kry op die vraag na die oorsprong van die Satan. Die probleem is egter dat die woord satan glad nie daar gebruik word nie. Daar word net van die slang gepraat, en dan op so 'n manier dat hy nie as 'n bo-menslike mag voorgestel word nie. Hy is wel 'n wese wat skynbaar meer weet as die mens, maar die klem lê eerder op die feit dat die kwaad deur middel van 'n skepsel van God die wêreld binnegekom het. Dis waar dat latere besinning die slang van Genesis 3 as die beliggaming van die Satan gesien het - vergelyk maar Openbaring 12:9 - en dat sy meerdere kennis, sy sluheid, verleiding, opstekery teen God en die stryd tussen hom en die mensdom (Gen 3:15) almal elemente is wat aan die Satan gekoppel word. Tog 
word die naam satan nooit gebruik nie. Die klem hier in Genesis is ietwat anders. In plaas daarvan om te sê dat die kwaad 'n mag is wat die mens oorweldig en waarteen hy haas geen verweer het nie, wil Genesis 3 dit beklemtoon dat die mens nie daaraan uitgelewer is nie. Hy kan nog kies of hy die kwaad wil doen of nie. Daarmee bring Genesis 3 die verantwoordelikheid van die mens self baie skerp in die gesigsveld. Omdat hierdie deel dus die mens se eie verantwoordelikheid wil beklemtoon eerder as die mag van 'n bomenslike wese, maar veral omdat die woord satan glad nie hier voorkom nie, moet dit liewers buite rekening gelaat word by die bepaling van die oorsprong van die Satan. Hoogstens kan gesê word dat dit terugskouend elemente toon wat eie aan die Satan is.

\subsubsection{Jesaja 14:11-17}

Dis verbasend hoe baie mense onder die indruk verkeer dat Jesaja 14:11-17 die oorsprong van die Satan beskryf. Die woorde in vers 12 "Jy wat die helderste môrester was, het uit die hemel geval" word dan deur hierdie persone soos volg verklaar: Die Satan was oorspronklik 'n engel van God, trouens die vernaamste engel, want daar staan mos "die helderste môrester". Hy het teen God in opstand gekom, want daar staan ook in vers 14 "ek word soos die Allerhoogste self". Daarom is hy uit die hemel verban, soos vers 14 lui "uit die hemel geval". Hierdie verklaring neem allerlei vorme aan en het ook die basis vir allerlei mooi verhaaltjies geword.

Maar so 'n verklaring klink net reg as 'n mens selektief sekere sinne gebruik en ander verswyg. Lees 'n mens die hele gedeelte, dan word dit oor en oor beklemtoon dat dit hier gaan oor die stad Babel wat so groot en ryk geword het dat dit vergelyk kon word met die môrester. Soos die môrester die blinkste van al die sterre is, so was Babel die glorierykste van al die stede, maar Babel het van sy mag misbruik gemaak: hy het vir hom mag toegeëien wat net aan God toekom. En omdat hy sodoende God na die kroon gesteek het, gaan God die stad verwoes. Dit sal wees soos die môrester wat skielik uit sy plek in die hemelruim neertuimel. Om dit baie duidelik te maak dat dit oor Babel gaan, staan daar in vers 22: "Ek sal maak dat die gedagtenis aan die koning van Babel verdwyn, dat daar niks van hom oor is nie... ." Omdat dit dus sonder twyfel ne oor die Satan gaan nie, maar oor die groot verdrukker, Babel, daarom kan hierdie deel nie gebruik word om te probeer vasstel waar die Satan vandaan kom, wie hy is en hoe hy te werk gaan nie.

Sommige mense wil hierdie deel koppel aan Lukas 10:18: "Ek het die Satan soos'n weerligstraal uit die hemel sien val." Sulke verklarings is ook totaal ongeoorloof. 'n Mens kan tog nie bloot op grond van die woorde "uit die hemel sien val" die twee dele aan mekaar gelykstel nie.

\subsubsection{Esegiël 28:2-6 en 11-19}

Daar is sommige mense wat meen dat Esegiël 28 na die Satan verwys. Gewoonlik 
word die volgende ter stawing aangehaal:

\begin{abstract}
"In jou hooghartighcid het jy gesê: 'Ek is 'n god, ek woon op die woonplek van die gode, omring deur die see'" (vers 2). "Jy was 'n secl wat met sorg vervaardig is, 'n praglige produk van volmaaktc vakmanskap: $\mathrm{jy}$ is uitgetceld in dic godctuin Eden, omring deur kosbare edelstene..." (verse 12-13). "Jy is uilgebeeld as die gerub wat met uitgestrekte vlerke moes waghou, Ek het jou opdrag gegec. Jy was op die heilige godcherg ..." (vers 14). "Jou optrede was onbesproke vandat jy geskep is totdat jy onreg begin doen het ..." (vers 15). "Daarom het Ek jou verstoot van die godeberg af ..." (vers 16).
\end{abstract}

Wanneer ' $n$ mens hierdie dele so in isolasie van die res lees, kry ' $n$ mens inderdaad die indruk dat hier gepraat word van 'n hemelse wese ('n gerub) wat onberispelik was en in die hemel ("godetuin Eden", "heilige godeberg") gewoon het, maar geval het ("totdat jy onreg begin doen het") en toe uit die hemel verban is ("jou verstoot van die godeberg af").

Maar is dit wat die gedeelte wil sê? Die hoofstuk vorm deel van 'n hele reeks oordele oor volkere wat rondom Israel woonagtig was, naamlik Ammon, Moab, Edom, Filistea, Tirus, Sidon en Egipte. Vanaf 26:1 tot 28:19 gaan dit oor Tirus en hierdie stad se oortredings. In 26:2 word die Godspraak ingelui met die woorde:

Mens, sẻ vir die regeerder van Tirus: So sê die Herc my (iod: In jou hooghartigheid hel jy gesế: 'Ek is 'n god, ck woon op die woonplek van die gode, omring deur die sec'".

Hieruit is dit duidelik dat die koning van die welvarende handelstad Tirus aangespreek word. Hy het homself aangematig om soos 'n god te heers op die eiland aan die kus van Palestina. Hierdie selfvergoddeliking, 'n kenmerk van baie konings destyds, was die vernaamste oortreding. Daarom volg die woorde: "Maar jy is 'n mens, nie 'n god nie. Jy het jou verbeel dat jy 'n god is ... ."

Dat dit hier om 'n mens gaan, blyk ook uit verse 6-9. Daar word die oordeel teen 'n mens aangekondig en gesê dat dit deur mense sal plaasvind:

"Daarom," sê die Here my God, 'omdat jy jou verbeel het jy is 'n god, daarom gaan Ek ander nasies, wrede volkc, teen jou laat optrek. Hulle sal die prag wat jou wysheid vir jou gebring het, met die swaard aanval en jou prag skend. Hulle sal jou in die graf in laat stort daar op jou eiland in die see ... Vir diE wat vir jou dond gaan sorg, sal jy 'n mens wees, nie 'n god nic ..."

Die treurlied oor hierdie koning en stad Tirus word in vers 12 weer ingelui met die pertinente aanspreek van die koning:

"Mcns, sing 'n trcurlied cor dic koning van Tirus.

Sê vir hom: So sê die Here my God ..."

Die treurlied vanaf vers 11 gaan nou nog verder met die beeld van 'n koning wat hom aanmatig om 'n god te wees. In hierdie treurlied word gebruik gemaak van 'n ou mite van destyds, naamlik dat gode op 'n berg woon, en word dit toegepas op die koning van Tirus (waarskynlik Itobaäl II). Elemente uit die Bybelse verhaal van die tuin van Eden waar die eerste mensepaar hulle teen God verhef het, word nou bygebring om die 
ironiese in die aanspraak van Itobaäl II skerper te benadruk en sodat die Israelitiese leser die parallel met die eerste mensepaar kan opmerk.

Hierdie koning van Tirus is op die koninklike seël as 'n gerub in 'n godetuin uitgebeeld. Hy stel homself voor as 'n god wat op die godeberg (die eiland Tirus) woon, soos die eerste mensepaar. Hulle het nie die tuin opgepas (Gen 2:15) nie, maar hulle teen God verhef deur hulle te vergryp aan die simbool van God in die tuin (die twee besondere bome). Hierdie koning het dieselfde pad geloop vanaf "onbesproke" tot "onreg" (vgl. "heiligdomme ontwy", Eseg. 28:18). Daarom sal hy, net soos die eerste mensepaar uit die tuin verban is, ook van die "godeberg" "verstoot" word - hy wat eintlik die bewaker van die stad (die gerub, vgl. Gen. 3:24) moes gewees het. Dit sal gebeur deurdat die koning "op die grond gegooi" word (vers 17) en die stad verower word (vers 18).

Hiermee sinspeel die hele gedeelte op Nebukadnesar se beleëring van die eilandstad Tirus en die gevangeneming van Itobaäl in die jaar 573 v.C. Van 'n beskrywing van die Satan as ' $n$ besondere hemelse wese wat in sonde verval het en toe uit die hemel verban is, is hier absoluut geen sprake nie. So 'n afleiding kan alleen gedoen word indien bepaalde verwysings in die teks en die historiese konteks geignoreer word, terwyl bepaalde gelykklinkende uitdrukkings op grond van 'n foutiewe uitleg van Jesaja 14 hier ook weer op die Satan van toepassing gemaak word.

\subsubsection{Konings 22:21-23}

Nog 'n grensgeval in die Ou Testament is 1 Konings 22:21-23. Daar vertel Miga, seun van Jimla (nie die profeet van die boek Miga nie), vir Koning Agab dat hy 'n visioen gesien het van ' $n$ hemelse vergadering. Tydens die vergadering het die Here onder die hemelinge 'n vrywilliger gesoek wat Agab sou oortuig om oorlog teen die stad Rama te maak sodat hy daar kon sneuwel. Toe het "die gees" na vore gekom en gesê hy sal 'n "leuengees" word in die mond van die hofprofete en deur middel van hulle optimistiese uitsprake die koning oortuig om die oorlog te voer.

Dic vraag word vervolgens gevra of ons nie hier met die Satan of minstens 'n bose gees te doen het nie. Hierteenoor moet ons die volgende in aanmerking neem: die kenmerkende van die Satan en die Bose is dat hy die wil van God weerstaan en as aanklaer van die mens optree. Hier vind ons presies die teenoorgestelde. Die "gees" doen juis dit wat God verlang. Daarom kan ons nie die "leuengees" met die Satan gelykstel nie. Eerder moet dit verstaan word in die lig van die oortuiging in die Ou Testament dat God só groot is dat niks, selfs nie eens die dood van 'n mens buite sy wil om gebeur nie.

Dit beteken nie dat God Agab willens en wetens verlei het en dat dit die oorsaak van sy dood was nie. Nee! Teenoor die "leuengees" stel God ook die woord van Miga. Agab het 'n keuse om te maak. Uit sy eie woorde en optrede is dit duidelik dat hy 
goed weet dat Miga die woord van die Here praat. Die stuur van die "leuengees" moet dus nie gelykgestel word met die verleiding van die Satan nie, maar is 'n geleentheid vir Agab om self te kies. Daarmee word beklemtoon dat die mens nie aan die kwaad uitgelewer is nie, maar dat hy in die laaste instansie nog die kwaad teen die goeie kan opweeg. Dit benadruk ook dat die kwaad dikwels die gevolg is van die mens se eie begeertes. As God se woord verontagsaam word ten einde die eie strewes na te jaag, lei dit noodwendig na onheil.

\subsection{Verwysings na die Satan}

Die Hebreeuse woord satan word in die Ou Testament meestal gebruik vir enige menslike teenstander of vyand. In Psalm 38:21; 55:4; 71:13; 109:4 word die woord in terme van vyand gebruik. (Die vertaling gebruik die woord "vyand", maar in die Hebreeus staan daar letterlik "satan".) Die betekenis van militêre of politieke teenstander kry ons weer in 1 Samuel 29:4, 1 Konings 5:4 en 11:14.

Die gebruik van die woord in die sin van ' $n$ wese wat verband hou met die kwaad kry ons net op drie plekke in die Ou Testament: in Sagaria 3:1-2, Job 1 en 2, en 1. Kronieke 21:1.

\subsubsection{Sagaria 3:1-2}

In Sagaria 3:1-2 is satan nog nie 'n eienaam nie. Dit word met die lidwoord die geskryf en is dus streng gesproke 'n soortnaam. Miskien moet 'n mens eerder sê dis 'n funksionele aanduiding, want vers 1 dui die funksie van die Satan aan, naamlik dat hy die hoëpriester Jesua aankla of teenstaan. Die werkwoord aankla en die soortnaam (en latere eienaam) satan is albei van presies dieselfde stam afgelei. Die Hebreeuse woord wat hier gebruik word, hassatan, moet dus verstaan word in die lig van die aanklag wat hy teen die hoëpriester ingebring het. Vervolgens meen geleerdes dat 'n mens hier die Hebreeuse woord eerder kan vertaal met die aanklaer, alhoewel sommige liewer die woord teenstander verkies.

Dis nie duidelik wat die aanklag was nie, maar die verwysing na die vuil klere van Jesua in vers 3 het geleerdes laat dink dat dit betrekking moes hê op die onwaardigheid of onbevoegdheid van Jesua om as hoëpriester op te tree. Drie belangrike dinge word hier duidelik. Die een is dat die Satan die aanklaer of teenstander van God se verbondskinders is. Hy is dus nie soseer 'n teenstander van God nie, maar veral van God se mense. Die tweede salak is dat hierdie wese nie op gelyke voet met God is nie. Hy voer nie die mag oor die hoëpriester nie, maar kan hom net beskuldig. Die derde saak is dat God sy eie oordeel vel en in hierdie oordeel juis sy liefde en genade laat blyk. In plaas daarvan om na aanleiding van die aanklag summier die hoëpriester skuldig te vind, tree God in die bresse vir Jesua. Hy neem sy skuld weg en bevestig sy posisie as bemiddelaar tussen God en die volk. Jesua is met ander woorde weer in ere herstel ten spyte van die waarskynlik gegronde aanklag van die Satan. 


\section{2 .2 Job 1 en 2}

In Job 1 en 2 vervul die Satan 'n feitlik soortgelyke funksie, naamlik as aanklaer van God se getroue kinders. Soos in die geval van die visioen van Miga, seun van Jimla, word die toneel voorgestel as 'n hemelse hofhouding. En soos in die geval van Sagaria 3:1-2 word die woord ook nog nie in die vorm van 'n eienaam geskryf nie. Die opvallende is dat die Satan skynbaar vrye toegang het tot hierdie hemelse hofhouding. Nog steeds word hy nie as 'n teenhanger van God gestel nie, maar eerder as 'n soort aanklaer van die vromes. Die saak wat hier baie sterk beklemtoon word, is dat die Satan geen mag oor God se kinders kan uitoefen sonder God se toestemming nie. Vir elke ding wat Satan teen Job doen, moet hy eers verlof kom vra.

Die optrede van God in die boek Job verskil met dié in Sagaria 3:1-2. In Sagaria het God vir die hoëpriester in die bresse getree; hier lyk dit of God dit nie doen nie, maar die Satan toelaat om maar sy gang te gaan. Dis natuurlik nie heeltemal waar nie, want God stel 'n beperking op die Satan se handelswyse teenoor Job. Die rede vir die verskil tussen Sagaria 3 en Job lê in die doel van elke Skrifdeel. Hier in Job is die doel om aan te toon dat ellendes en teleurstellings nie noodwendig aan sonde gewyt moet word nie. In Job se geval gaan dit onder meer oor die verskil tussen Godsvrug en selfsug.

Die boek Job vertel dat die Satan nie geslaag het in sy poging om aan te toon dat Job se vroomheid eintlik maar bedekte selfsug was nie. Tog, vreemd genoeg, is daar nie weer enige verdere sprake van die Satan nie. 'n Mens sou verwag dat daar minstens in die laaste hoofstuk van die boek weer oor hom gepraat sou word, dat hy daar tot orde geroep sou word. Tog word daar absoluut niks verder van hom gesê nie. Dis duidelik dat die bedoeling nie is om ons ' $n$ beeld van die Satan te gee nie. Die Satan vervul hier ' $n$ bepaalde funksie en as dit afgeloop is, is dit nie meer belangrik om verder oor hom te praat nie. Per slot van rekening gaan dit eintlik oor Job en sy verhouding met God en nie oor die Satan nie.

Al wat ons uit die boek Job oor die Satan te wete kom is die volgende: hy is 'n wese wat die vromes valslik aankla; hy het toegang tot God; hy beskik oor baie mag, maar hy is steeds aan God onderworpe.

\subsection{Kronieke 21:1}

Die laaste gedeelte in die Ou Testament waar daar uitdruklik sprake is van die Satan, is 1 Kronieke 21:1. Daar staan die volgende: "Satan was teen Israel. Hy het Dawid aangehits om 'n sensus van Israel te hou."

Hierdie hele hoofstuk is 'n parallel van 2 Samuel 24:1-25. Alhoewel die twee hoofstukke inhoudelik grootliks met mekaar ooreenstem, is daar tog groot verskille. Een daarvan is juis vers 1 . In 2 Samuel 24:1 staan daar: "Op 'n keer was die Here 
vertoorn op Israel. Hy het Dawid teen hulle aangehits en gesê: 'Gaan tel die Israeliete en die Judeërs'."

Die Samuelteks sê die Here het Dawid aangehits en die Kronieketeks sê Satan het dit gedoen. Om hierdie skynbare teenstrydigheid te verstaan, moet 'n mens in ag neem dat daar ' $n$ groot verskil in ouderdom bestaan tussen die twee boeke. Waar dele van Samuel uit die tyd vóór die ballingskap is, is Kronieke ná die ballingskap as een van die laaste boeke van die Ou Testament geskryf. Daar bestaan ook 'n groot verskil in die doel waarom die twee boeke geskryf is.

As 'n mens dit in ag neem, word die volgende duidelik. In die vroeë tyd was Israel sterk onder die indruk dat die Here algeheel soewerein is: daar is niks of niemand wat sy gelyke is nie. Selfs ook die kwaad is nie 'n mag wat teenoor Hom staan nie, maar is geheel en al aan Hom onderworpe. Dit blyk duidelik uit die voorbeelde uit Sagaria en Job. Mettertyd het hierdie insig egter probleme begin oplewer: byvoorbeeld, hoe rym 'n mens dan die kwaad met God se goedheid en heiligheid? Geleidelik het daar 'n nuwe insig gekom, naamlik dat daar ook 'n selfstandig-werkende bose mag, 'n wese is wat vir die kwaad verantwoordelik is. Vandaar dat die ouere weergawe in Samuel kon * sê dat God Dawid aangehits het, terwyl die latere vertelling in Kronieke sê dit was Satan. Ons kan dus sê dat die kennis oor Satan voortgevloei het uit 'n dieper sedelike begrip van God, naamlik dat Hy te heilig is om met die kwaad gemoeid te wees. Die Bose kan nie van Hom afkomstig wees nie en vind nou gestalte in Satan. Intussen het die benaming Satan ook die die verloor en word dit as 'n eienaam gebruik.

\section{SAMEVATTEND}

Samevattend kan ons dus sê dat die Ou Testament ons eintlik baie min oor die Satan meedeel. Hy is 'n wese wat vir die kwaad verantwoordelik is, maar meestal op so 'n wyse dat hy nooit as 'n teenhanger van God geteken word nie; hy is totaal aan God onderworpe. Om nou aan die Satan 'n statuur te verleen wat gelyk is aan (en in sommige gevalle verhewe is bo) God, staan in skrille kontras met wat die $\mathrm{Ou}$ Testament leer en tas die soewereiniteit van God aan.

Oor die vraag waar Satan vandaan kom, sê die Ou Testament absoluut niks nie. Die oorsprong van die kwaad bly dus 'n tergende geheim. Daarteenoor is die werklikheid van die Bose 'n daaglikse ervaring. Dis egter nie 'n mag wat gevrees moet word nie, maar wat herken moet word sodat die mens in sy besluitneming duidelik ten gunste van God kan kies.

Maar dit word ook duidelik dat die Ou Testament daarteen wil waak dat mense hulle verantwoordelikheid in die keuse van die kwaad te maklik op die Satan se rekening wil afskuif. Dis waar dat daar bose magte is, maar in die laaste instansie moet die mens self besluit hoe hy gaan reageer op die werking van die Bose. Daartoe help God die mens deur sy wil aan hom bekend te maak. Om nou die Satan te blameer vir alles wat met die mens verkeerd gaan, sou in teenspraak wees met wat die Ou Testament wil 
beklemtoon en is 'n aantasting van die mens se vryheid en sy verantwoordelikheid voor God. In die laaste instansie is dit 'n aantasting van die noodsaaklikheid van verlossing en die werk van Christus.

Aan die ander kant wil die Ou Testament die gelowiges ook die versekering gee dat hulle nie uitgelewer is aan die willekeur van die Bose nie. Geen ander wese kan teen God se wil in teen die gelowiges optree, so asof God se mag beperk is nie. Bowe-al het die gelowiges die versekering dat, al sou die Satan hulle ook teenstaan en aankla, God se genade en liefde só groot is dat Hy kan vergewe en die mens in 'n nuwe verhouding met Hom kan plaas ten spyte van die werking van die Bose. Hierdie vergifnis deur Jesus, hierdie nuwe verhouding met God moet egter in die teken staan van die oorwinning van Jesus. Sy vergifnis en herskepping loop uit op oorwinning - oorwinning oor sonde, oor die dood, oor my vrees, oor my verlede, oor my swakhede, oor my begeertes en teleurstellings, maar ook oor die Satan en alle bose magte. As gelowiges kan en moet ons dus die lewe tegemoet gaan, nie met 'n vrees vir die Satan nie, maar in die krag van hierdie triomf van God in Jesus.

\section{LTTERATUUR WAT GERAADPLEEG KAN WORD}

BRONGERS, HA. 1\%67. I Koningen. Nijkerk : Callenbach. BRUEGGEMANN, W. 1982. Genesis. Allanta : John Knox. CLEMENTS, R.E. 1980. Isaiah 1-39. Grand Rapids : Eerdmans.

DE BLOIS, K.F. 1986. How to deal with Satan? The Bible Translator, 37(3):301-309.

EICHRODT, W. 1970. Ezekiel. London : SCM.

ELIADE, M. ed. 1987. Demons: An Overview. (In Encyclopedia of Religion. Vol. 4. New York : Macmillan. p. 284-285.)

FOHRER, G. 1972. History of Israelite Religion. New York : Abingdon.

GREEN, M. 1981. I Believe in Satan's Downfall. London : Hodder \& Stoughton.

MAARSINGH, B. 1980. Leviticus. Tweede herziene druk. Nijkerk : Callenbach.

MONTGOMERY, J.W. ed. 1976. Demon Possession. Minneapolis : Bethany.

ROUBOS, K. 1972. II Kronieken. Nijkerk : Callenbach.

SNIJDERS, LA. 1969. Jesaja deel I. Nijkerk : Callenbach.

THEOLOGISCHE REALENCYKLOPaDIE BAND VIII. 1981. Berlin : De Gruyter.

VAN SELMS, A. 1982. Job decl 1. Nijkerk : Callenbach.

VOSLOO, W. 1988. Die tuinverhaal. 'n Narratologiese ondersock van Genesis 2-3. (In Prinsloo, W.S. \& W. Voslon reds. In menselaal oor God se Woord. Huldigingsbundel opgedra aan professor A.H. van Zyl. Kaapstad : Lux Verbi. p. 158-174.)

VRIEZEN, Th.C. 1\%66. Hoofdlijnen der theologie van het Oude Testament. Derde druk. Wageningen : H. Veenman \& Zonen.

WESTERMANN, C. 1984. Genesis 1-11. Minneapolis : Augsburg.

WILDBERGER, H. 1978. Jesaja Kapitel 13-27. Neukirchen : Neukirchener-Vluyn.

WENHAM, GJ. 1979. The Book of Leviticus. London : Hodder \& Stoughton.

WEVERS, J.W. 1982. Ezckiel. (Softback edition.) Grand Rapids : Eerdmans.

WRIGHT, N. 1990. The Satan Syndrome. Pulting the Power of Darkness in Its Place. Grand Rapids : Academie. 